Supporting Information

\title{
Conjugated Polymer Nanogels Binding Anticancer Drug Through Hydrogen Bonds for Sustainable Drug Delivery
}

\author{
Thangaraj Senthilkumar, ${ }^{a}$ Fengting Lv, ${ }^{a} *$ Hao Zhao, ${ }^{a, b}$ Libing Liu, ${ }^{a}$ and Shu Wang ${ }^{a, b}$ \\ ${ }^{a}$ Beijing National Laboratory for Molecular Sciences, Key Laboratory of Organic Solids, \\ Institute of Chemistry, Chinese Academy of Sciences, Beijing, 100190, P. R. China \\ ${ }^{\mathrm{b}}$ College of Chemistry, University of Chinese Academy of Sciences, Beijing 100049, P. R. \\ China
}

Email: lvft@iccas.ac.cn

\section{Experimental}

Materials and Measurements: All chemicals were purchased from Aldrich Chemical Company, Acros, Alfa-Aesar or J\&K Scientific LTD and used as received. All organic solvents were purchased from Beijing Chemical Works and used as received. HeLa cells were obtained from cell culture center of Institute of Basic Medical Sciences, Chinese Academy of Medical Sciences (Beijing, China). Fetal bovine serum (FBS) was purchased from Sijiqing Biological Engineering Materials (Hangzhou, China). Dulbecco's Modified Eagle Medium (DMEM) and phosphate buffer saline (PBS) were purchased from Hyclone (Beijing, China). Water was purified with a Millipore filtration system. Compounds 1, 3 and 6 were prepared according to the literature procedures, respectively. ${ }^{1-3}$ The ${ }^{1} \mathrm{H}$ NMR and ${ }^{13} \mathrm{C}$ NMR were performed by Bruker Avance 300 or $400 \mathrm{MHz}$ spectrometer. MALDI-TOF analysis was obtained using Bruker Auto Flex system. UV-Vis absorption spectra were measured on JASCO V-550 spectrophotometer. Fourier transform infrared (FT-IR) spectroscopic 
measurements were performed in Nicolet 6700 spectrometer from Thermo Scientific at $1 \mathrm{~cm}^{-1}$ resolution. Fluorescence spectra were measured on Hitachi F-4500 fluorometer equipped with a xenon lamp excitation source. Photographs of nanogel were taken with a Canon EOS 450D Digital camera in UV analyzing equipment (WD-9430F) under $365 \mathrm{~nm}$. Scanning electron microscopy (SEM) was performed by Hitachi S-4800 scanning electron microscope. The free energy $(\Delta \mathrm{G})$ calculations were performed in Gaussian (09) software program using Density functional theory analysis. The viability analysis for estimating cytotoxicity was collected using a microplate reader (BIO-TEK Synergy HT, USA) at a wavelength of $490 \mathrm{~nm}$. Confocal laser scanning microscope (CLSM) characterization was conducted with confocal laser scanning biological microscope (FV1000-081, Olympus, Japan).

Synthesis of compound 2: Uracil (0.363 g, $3.23 \mathrm{mmol}), \mathrm{KI}(0.18 \mathrm{~g}, 1.077 \mathrm{mmol})$ and $\mathrm{K}_{2} \mathrm{CO}_{3}$ $(0.745 \mathrm{~g}, 5.39 \mathrm{mmol})$ were taken in two neck round bottom flask and dissolved the content in DMSO. Compound 1 ( $1 \mathrm{~g}, 1.077 \mathrm{mmol})$ was dissolved in DMSO and added to the reaction mixture via a syringe. The reaction mixture was heated to $90{ }^{0} \mathrm{C}$ for $6 \mathrm{~h}$. After completion of the reaction cool down the contents to room temperature and poured the mixture into water. The precipitate was collect by filtering in the Buckner funnel. The crude compound was purified by silica gel chromatography with $\mathrm{DCM} / \mathrm{MeOH}(95 / 5)$ as eluent to afford light brown solid. ${ }^{1} \mathrm{H}$ NMR (400 MHz, $\left.\mathrm{CDCl}_{3}\right) \delta 9.69$ (b, 2H), 7.33 (d, 2H), 7.10 (s, 2H), 5.59 (m, 2H), 4.07 (t, 4H), 3.87 (b, 4H), 3.70-3.57 (b, 24H). $\left.{ }^{13} \mathrm{C} \mathrm{NMR} \mathrm{(100} \mathrm{MHz,} \mathrm{CDCl}_{3}\right) \delta 165.53,152.69$, $148.21,147.49,120.68,111.72,110.28,102.56,72.48,72.13,69.74,66.29,51.04 . \mathrm{MS}$ (MALDI-TOF): calculated $831.464(\mathrm{M}+\mathrm{Na})$; observed $831.463(\mathrm{M}+\mathrm{Na})$.

Synthesis of compound 5: Doxorubicin hydrochloride (4) (50 mg, $86.2 \mu \mathrm{mol})$ and prop-2-yn1-ylhydrazine $(8.5 \mathrm{mg}, 0.121 \mathrm{mmol})$ were dissolved in dry methanol. This mixture was allowed to react in the presence of a drop of trifluoroacetic acid at $60{ }^{\circ} \mathrm{C}$ for 12 hours. 
$\mathrm{NH}_{4} \mathrm{OAc}$ buffer was added dropwise to neutralize the amine. Methanol was removed and the crude product was purified by silica gel column chromatography using DCM/methanol (90:10) as eluent to afford dark red solid. ${ }^{1} \mathrm{H}$ NMR $\left(400 \mathrm{MHz}, \mathrm{MeOH}-d_{4}\right) \delta 7.99(\mathrm{~d}, 1 \mathrm{H}), 7.85$ (t, 1H), $7.75(\mathrm{~m}, 3 \mathrm{H}), 7.60(\mathrm{~d}, 1 \mathrm{H}), 5.47(\mathrm{~d}, 1 \mathrm{H}), 5.12(\mathrm{bs}, 1 \mathrm{H}), 4.71(\mathrm{bs}, 2 \mathrm{H}), 4.30(\mathrm{q}, 1 \mathrm{H})$, $4.08(\mathrm{~d}, 2 \mathrm{H}), 4.05(\mathrm{~s}, 3 \mathrm{H}), 3.66(\mathrm{~s}, 1 \mathrm{H}), 3.60(\mathrm{~d}, 1 \mathrm{H}), 3.09(\mathrm{~d}, 1 \mathrm{H}), 3.03(\mathrm{~d}, 1 \mathrm{H}), 2.38(\mathrm{~d}, 1 \mathrm{H})$, $2.24(\mathrm{t}, 1 \mathrm{H}), 2.16(\mathrm{~s}, 3 \mathrm{H}), 2.05(\mathrm{~m}, 1 \mathrm{H}), 1.91,(\mathrm{~d}, 1 \mathrm{H}), 1.30(\mathrm{~d}, 3 \mathrm{H})$. MS (MALDI-TOF): calculated $618.2193(\mathrm{M}+\mathrm{Na})$; observed 618.2192.

Synthesis of Dox-Py: Compound $5(0.1 \mathrm{~g}, 0.158 \mathrm{mmol}) \mathrm{CuSO}_{4} \cdot 5 \mathrm{H}_{2} \mathrm{O}(39.55 \mathrm{mg}, 0.158$ mmol), compound (6) (55.6 mg, $0.238 \mathrm{mmol})$ were taken in two neck round bottom flask and degassed finally sealed with Ar. Dry tetrahydrofuran was added to reaction mixture and allow to stir at room temperature for $24 \mathrm{~h}$. All the content was poured into water and extracted with DCM twice. The combined organic layer was washed with water, brine and filtered. DCM was removed under reduced vacuum and the crude product was purified by the silica gel column chromatography to obtain dark red powder. ${ }^{1} \mathrm{H}$ NMR $\left(400 \mathrm{MHz}, \mathrm{CDCl}_{3}\right) \delta 8.42$ (bs, $1 \mathrm{H}), 8.25(\mathrm{~d}, 1 \mathrm{H}), 8.14(\mathrm{~d}, 1 \mathrm{H}), 7.95(\mathrm{~d}, 1 \mathrm{H}), 7.88(\mathrm{~d}, 1 \mathrm{H}), 7.77(\mathrm{bs}, 1 \mathrm{H}), 7.70(\mathrm{t}, 3 \mathrm{H}), 7.42(\mathrm{~s}$, 1H), $7.18(\mathrm{t}, 1 \mathrm{H}), 6.97(\mathrm{~d}, 1 \mathrm{H}), 5.35(\mathrm{~s}, 1 \mathrm{H}), 4.14(\mathrm{~s}, 2 \mathrm{H}), 4.08(\mathrm{~s}, 3 \mathrm{H}), 3.66(\mathrm{~s}, 1 \mathrm{H}), 3.33(\mathrm{~m}$, $1 \mathrm{H}), 3.00(\mathrm{~s} 2 \mathrm{H}), 2.69(\mathrm{t}, 3 \mathrm{H}), 2.46(\mathrm{~s}, 2 \mathrm{H}), 2.32$, (s, 2H), $2.27(\mathrm{~s}, 2 \mathrm{H}), 2.03(\mathrm{~s}, 3 \mathrm{H}), 1.25(\mathrm{~m}$, 3H). MS (MALDI-TOF): calculated 852.8124 (M+Na); observed 852.8120.

Molecular Weight Analysis by GPC: The molecular weight of the polymers PPV-U and PPV-C were analyzed with GPC using THF as eluent. The GPC chromatogram showed a single peak with broad distribution. The polymer sample was prepared by dissolving $2 \mathrm{mg} / \mathrm{mL}$ of THF and wait until complete dissolution. Samples are filtered through $0.45 \mu \mathrm{M}$ size PTFE filters before injection. Finally $100 \mu \mathrm{L}$ of sample is injected into the GPC through autosampler. 
SEM Studies: $20 \mu \mathrm{M}$ concentration of PPV-NG, Dox-Py and Dox-Py hydrogen bonded PPV-NG were used in SEM separately. Each analyte of drop $50 \mu \mathrm{L}$ aqueous solution of nanogels were casted on top of the silicon wafer and allowed it to evaporate under room temperature for $24 \mathrm{~h}$. Samples were sputtered with $1 \mathrm{~nm}$ thin layer of gold and analyzed under SEM microscope.

FT-IR Measurements: FT-IR measurements of PPV-U, Dox-Py and Dox-Py hydrogen bonded PPV-U were recorded using $5 \mathrm{mM}$ solutions in $\mathrm{CHCl}_{3}$ solvent. The PPV-NG and Dox-Py hydrogen bonded PPV-NG were recorded using 0.5-1 mm thick films of dried gels. The samples were recorded in absorbance mode and measured in the frequency range from 4000-500 $\mathrm{cm}^{-1}$ using $\mathrm{CaF}_{2}$ IR sample holder with $50 \mu \mathrm{m}$ thick Teflon spacer.

HPLC analysis: HPLC analyses of PPV-NG/Dox-Py, Dox-Py, Dox were performed with Waters HPLC system, equipped with a Waters 1525 binary pump, a Waters 2475 UV detector at $480 \mathrm{~nm}, 1500$ column heater, and a Symmetry C18 column. HPLC grade acetonitrile/water $(30 / 70, \mathrm{v} / \mathrm{v})$ with a flow rate of $1.0 \mathrm{~mL} / \mathrm{min}$.

Cell Culture: HeLa cells were cultured in Dulbecco's modified eagle medium (DMEM) supplemented with $10 \% \mathrm{FBS}$ at $37{ }^{\circ} \mathrm{C}$ in a humidified atmosphere containing $5 \% \mathrm{CO}_{2}$.

Cell Viability Assay Analyzed MTT Method: To test the cytotoxicity, HeLa cells were seeded in 96-well plates at a density of 60000 cells/well until adhered to the bottom surface and then incubated with Dox-Py hydrogen bonded PPV-NG nanogels at different concentrations of 0, $0.5,1,2,4,8,16,32,64 \mu \mathrm{M}$ under cell culture condition for $24 \mathrm{~h}, 48 \mathrm{~h}$ and $72 \mathrm{~h}$, separately. Subsequently, MTT agent $\left(0.5 \mathrm{mg} / \mathrm{mL}^{-1}\right.$ in medium, $100 \mu \mathrm{L} /$ well $)$ was added to the plates and after the supernatant solution was removed. Incubation was followed at $37{ }^{\circ} \mathrm{C}$ for $4 \mathrm{~h}$. The supernatant was removed and $100 \mu \mathrm{L}$ of DMSO per well was added to dissolve so formed 
crystals of formazan. After shaking the plates for $3 \mathrm{~min}$, absorbance values of the wells were read out with a microplate reader at the wavelength of $520 \mathrm{~nm}$.

\section{References}

[1] Y.-L. Zhao, L. Liu, W. Zhang, C.-H. Sue, Q. Li, O. S. Miljanic, O. M. Yaghi, J. F. Stoddart, Chem. Eur. J. 2009, 15, 13356.

[2] H. Fang, S. Wang, S. Xiao, J. Yang, Y. Li, Z. Shi, H. Li, H. Liu, S. Xiao, D. Zhu, Chem. Mater. 2003, 15, 1593.

[3] T. Senthilkumar, L. Zhou, G. Qi, L. Liu, F. Lv, S. Wang, Angew. Chem., Int. Ed. 2018, $57,13114$.

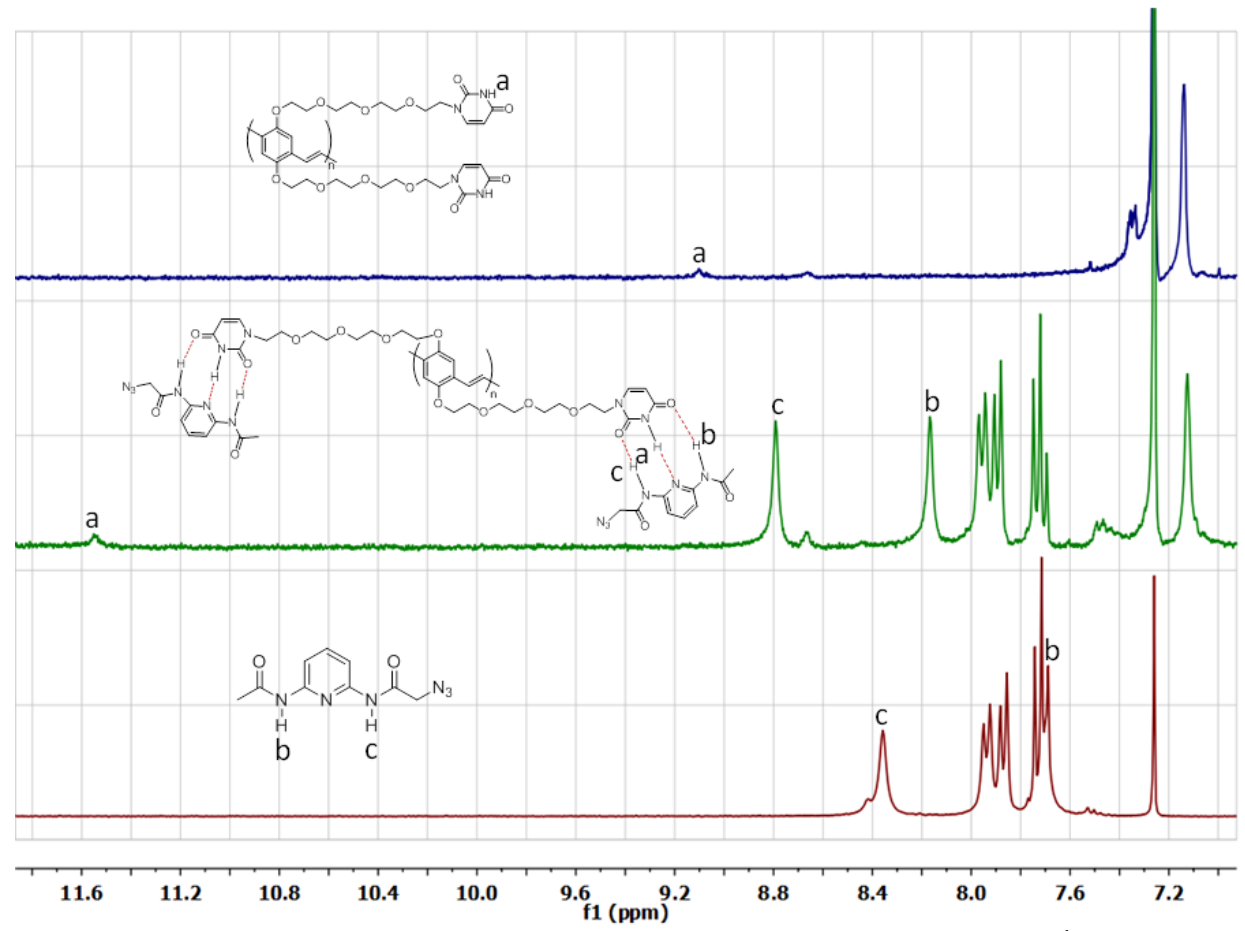

Figure S1. Hydrogen bonded complex of PPV-U with compound $6 .{ }^{1} \mathrm{H}$ NMR of PPV-U, compound 6 and compound 6 hydrogen bonded PPV-U in $\mathrm{CDCl}_{3}$ solvent. 


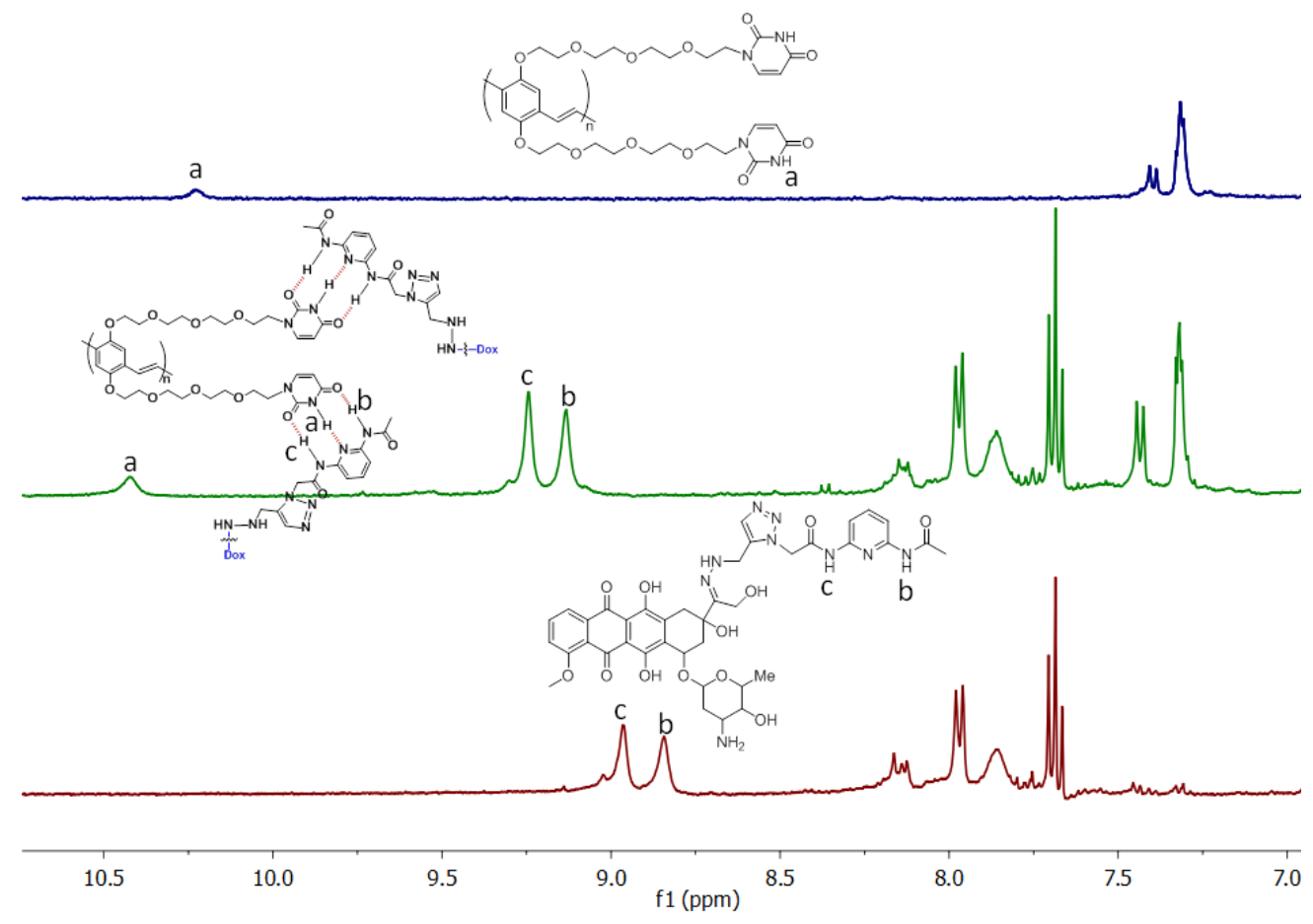

Figure S2. ${ }^{1} \mathrm{H}$ NMR of hydrogen bonded complex of PPV-U with Dox-Py in THF- $d_{8}$ $(90 \%)+\mathrm{D}_{2} \mathrm{O}(10 \%)$ solvent.
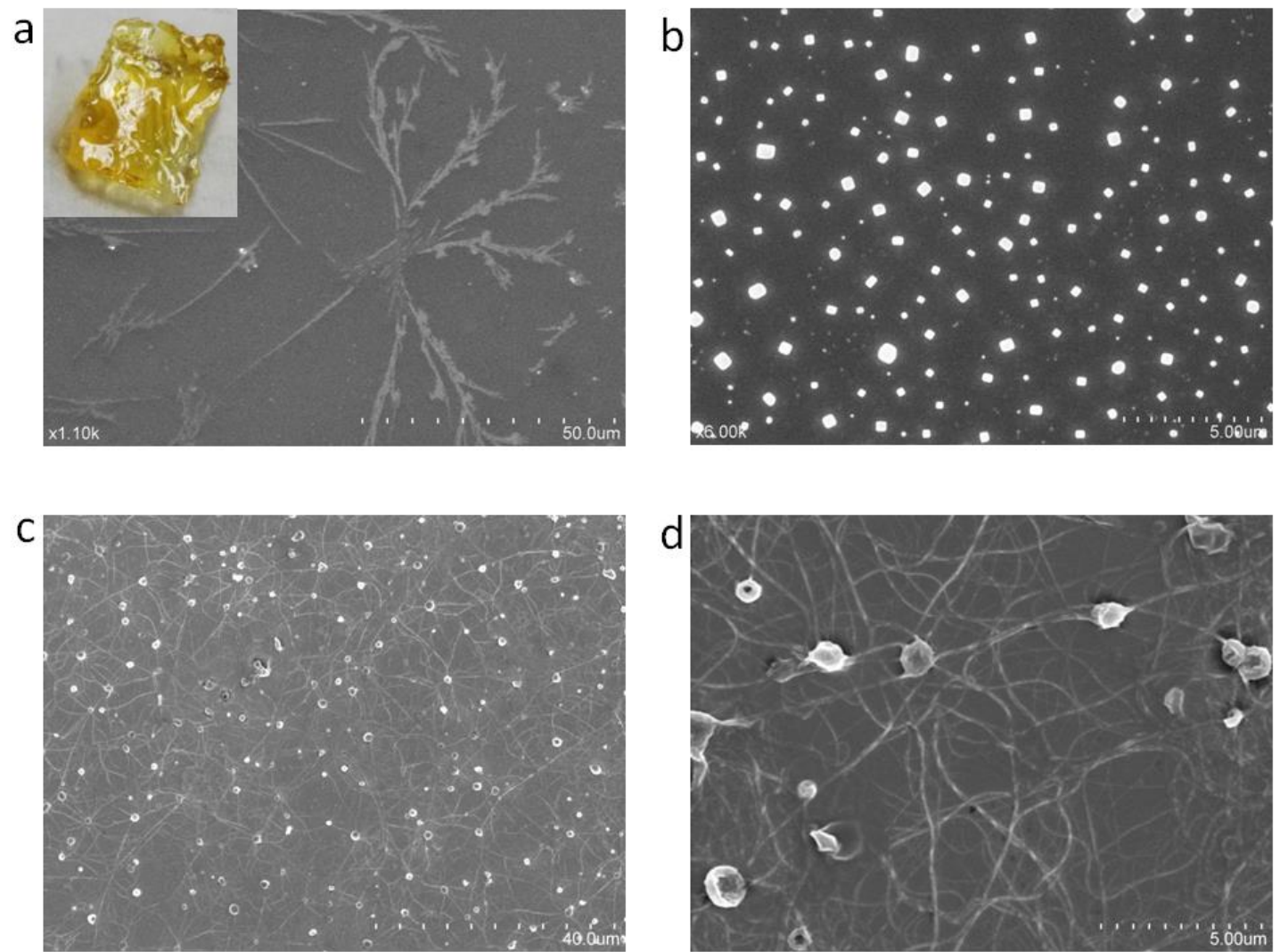
Figure S3. SEM images of PPV-NG (a), Dox-Py (b), and Dox-Py hydrogen bonded PPV-NG (c) and (d) with different magnifications.

Optimized structure front view

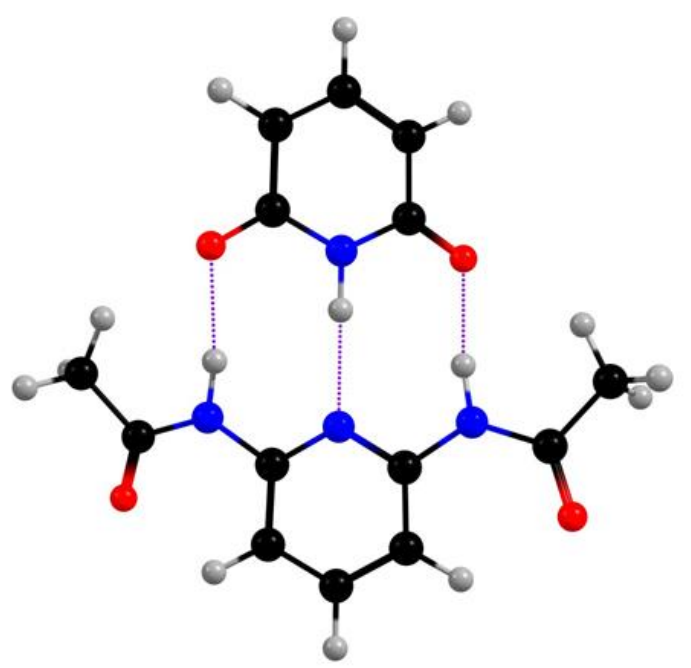

Optimized structure side view

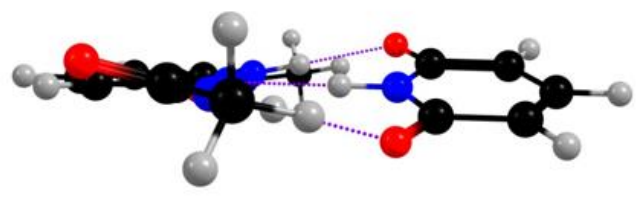

Figure S4. DFT optimized structure (front and side view) of uracil and 2,6-diamino pyridine hydrogen bonding complex in water.

Table S1. Free energies $(\Delta \mathrm{G})$ of uracil (fragment A ), 2, 6-diamino pyridine (fragment B), hydrogen bonded complex between uracil and 2, 6-diamino pyridine (fragment C) and the hydrogen bonding energy alone were calculated using DFT in different solvent.

Hydrogen bond energy $=[$ Fragment $\mathrm{C}-($ Fragment $\mathrm{A}+$ Fragment $\mathrm{B})] \times 627.51 \mathrm{kcal} / \mathrm{mol}$.

$\begin{array}{ccccc}\text { Solvent } & \text { Fragment A } & \text { Fragment B } & \text { Total molecule C } & \text { H-bond Energy } \\ \text { Water } & -398.25671871 \text { a.u. } & -664.54748039 \text { a.u. } & -1062.81524929 \text { a.u. } & -6.93 \mathrm{kcal} / \mathrm{mol} \\ \mathbf{T H F} & -398.25423823 \text { a.u. } & -664.54440937 \text { a.u. } & -1062.81139786 \text { a.u. } & -8.00 \mathrm{kcal} / \mathrm{mol} \\ \mathbf{C H C l}_{\mathbf{3}} & -398.25283673 \text { a.u. } & -664.54271925 \text { a.u. } & -1062.80926179 \text { a.u. } & -8.60 \mathrm{kca} / \mathrm{mol}\end{array}$

According to literature, the enthalpy values for hydrogen bonding between $\mathrm{N}-\mathrm{H} \cdots: \mathrm{N}(-13$ $\mathrm{kJ} / \mathrm{mol}$ or $3.1 \mathrm{kcal} / \mathrm{mol})$ and $\mathrm{N}-\mathrm{H} \cdots \mathrm{O}(-8 \mathrm{~kJ} / \mathrm{mol}$ or $-1.9 \mathrm{kcal} / \mathrm{mol})$ were calculated from 
molecular dynamics simulations (J. Emsley, Chem. Soc. Rev. 1980, 9, 91). The energy for triple hydrogen bonding between uracil and diamino pyridine was calculated as $-6.9 \mathrm{kcal} / \mathrm{mol}$.

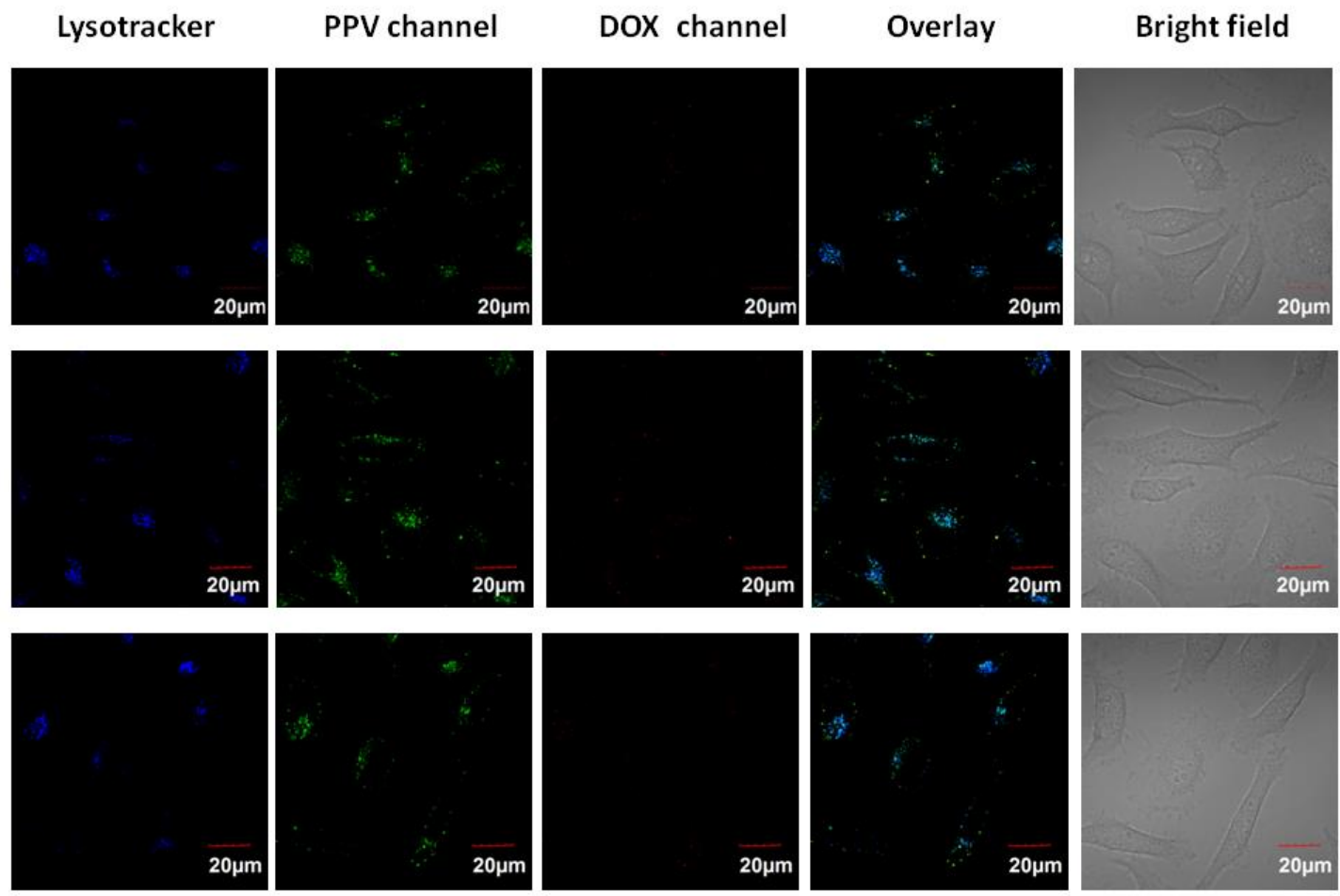

Figure S5. Cellular uptake of Dox-Py hydrogen bonded PPV-U polymer. Lysosomes were labeled with Lysotracker Blue.

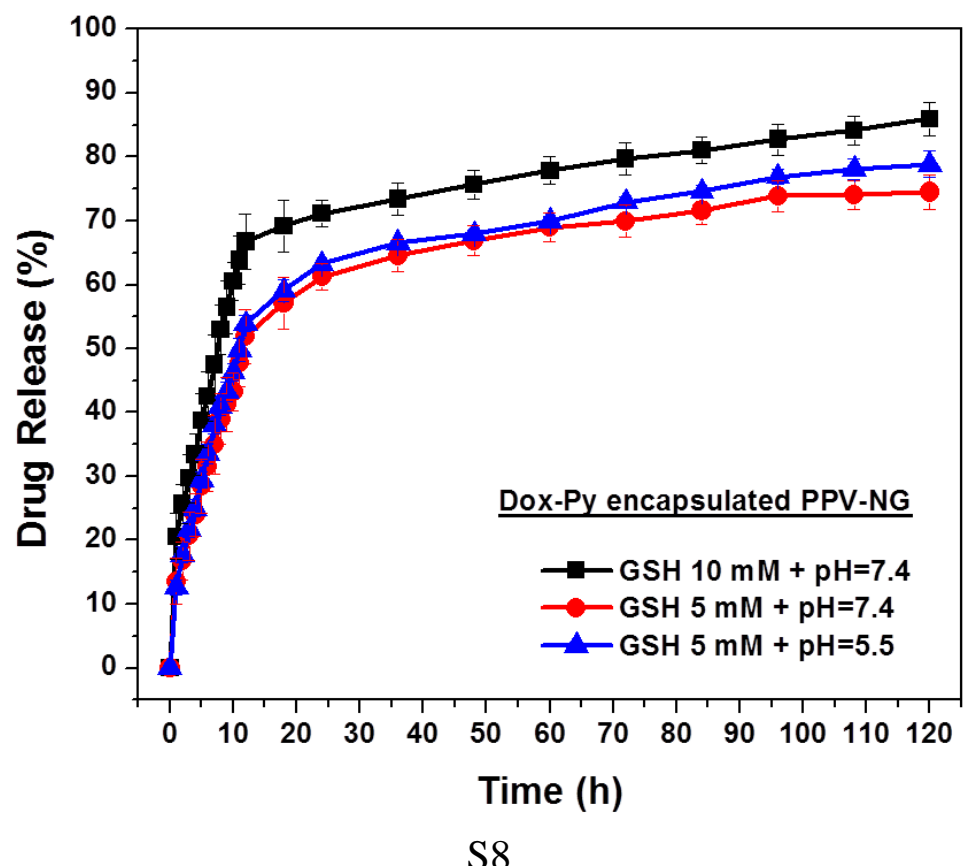


Figure S6. Drug release percentage of Dox-Py encapsulated PPV-NG as a function of time from 0 to $120 \mathrm{~h}$ in different conditions.

Figure S7 NMR data of compounds

(a) Compound-2 NMR recorded in $\mathrm{CDCl}_{3}$

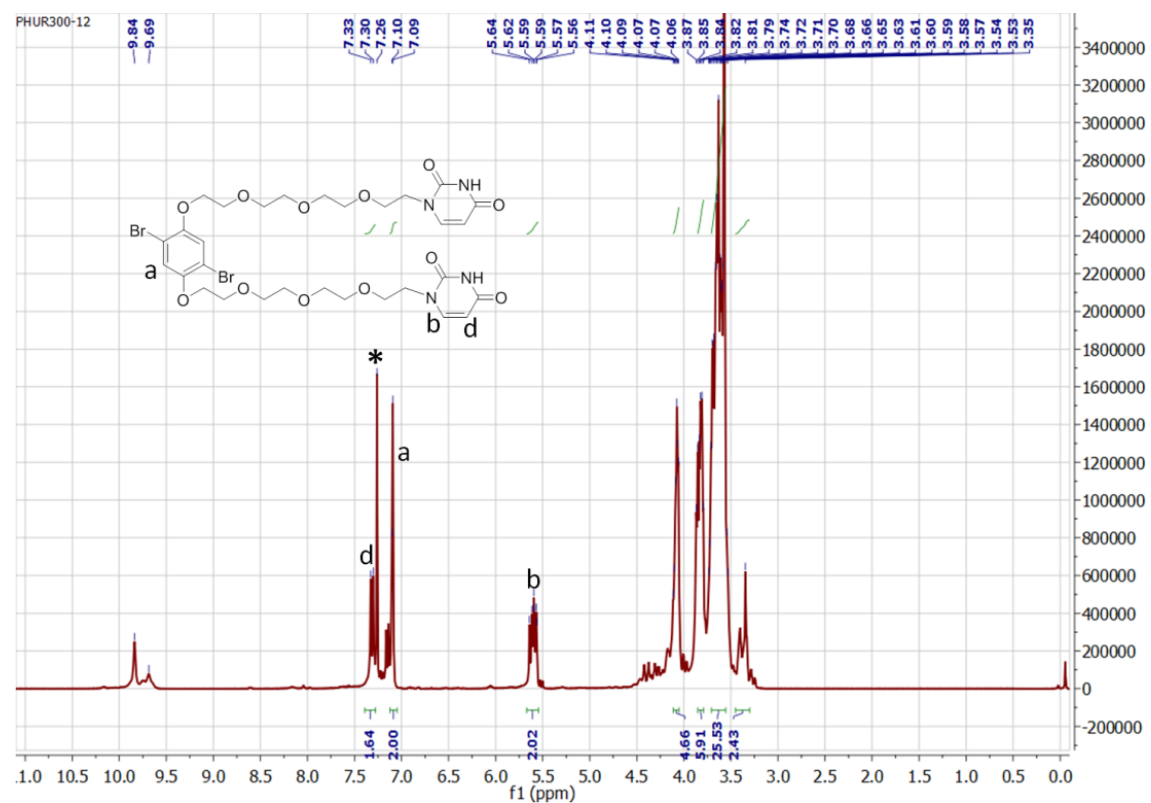

(b) PPV-U polymer NMR in $\mathrm{CDCl}_{3}$. 


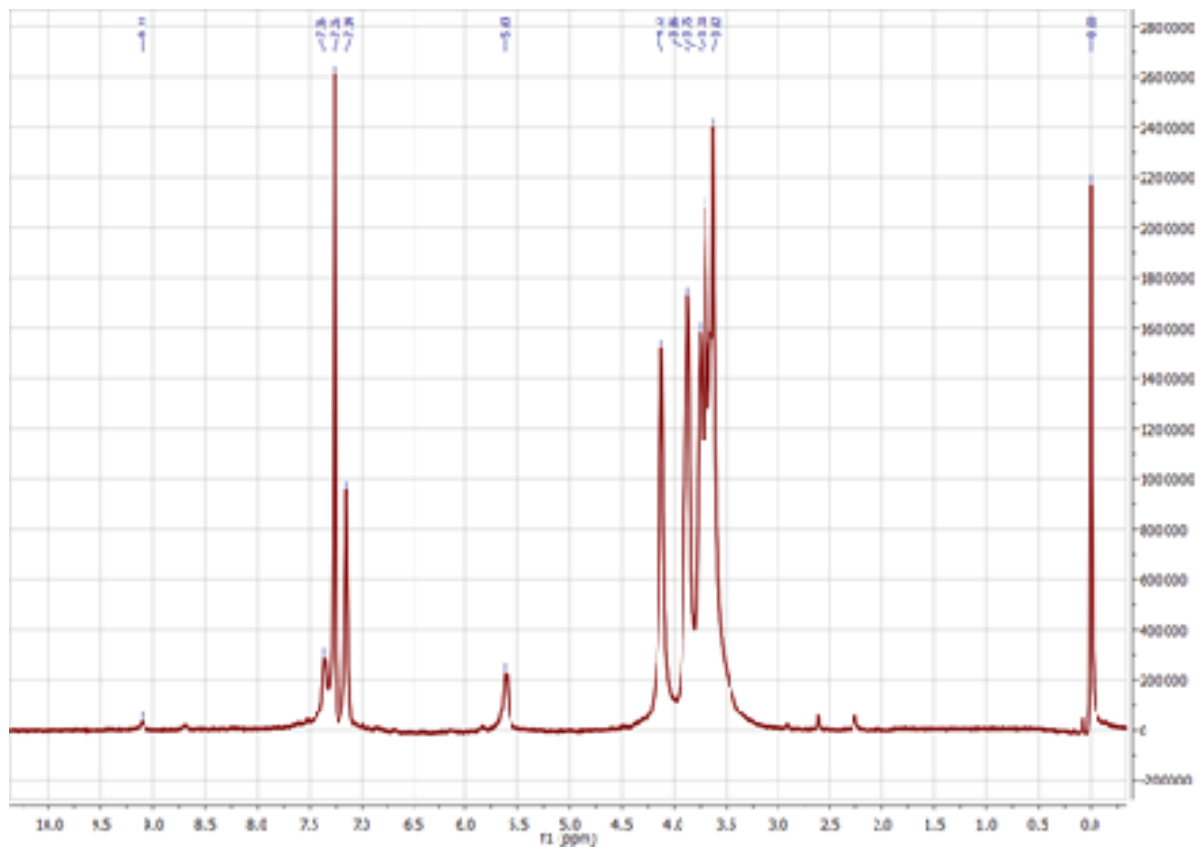

(c) Compound $5 \mathrm{NMR}$ in $\mathrm{MeOH}-\mathrm{d} 4$.

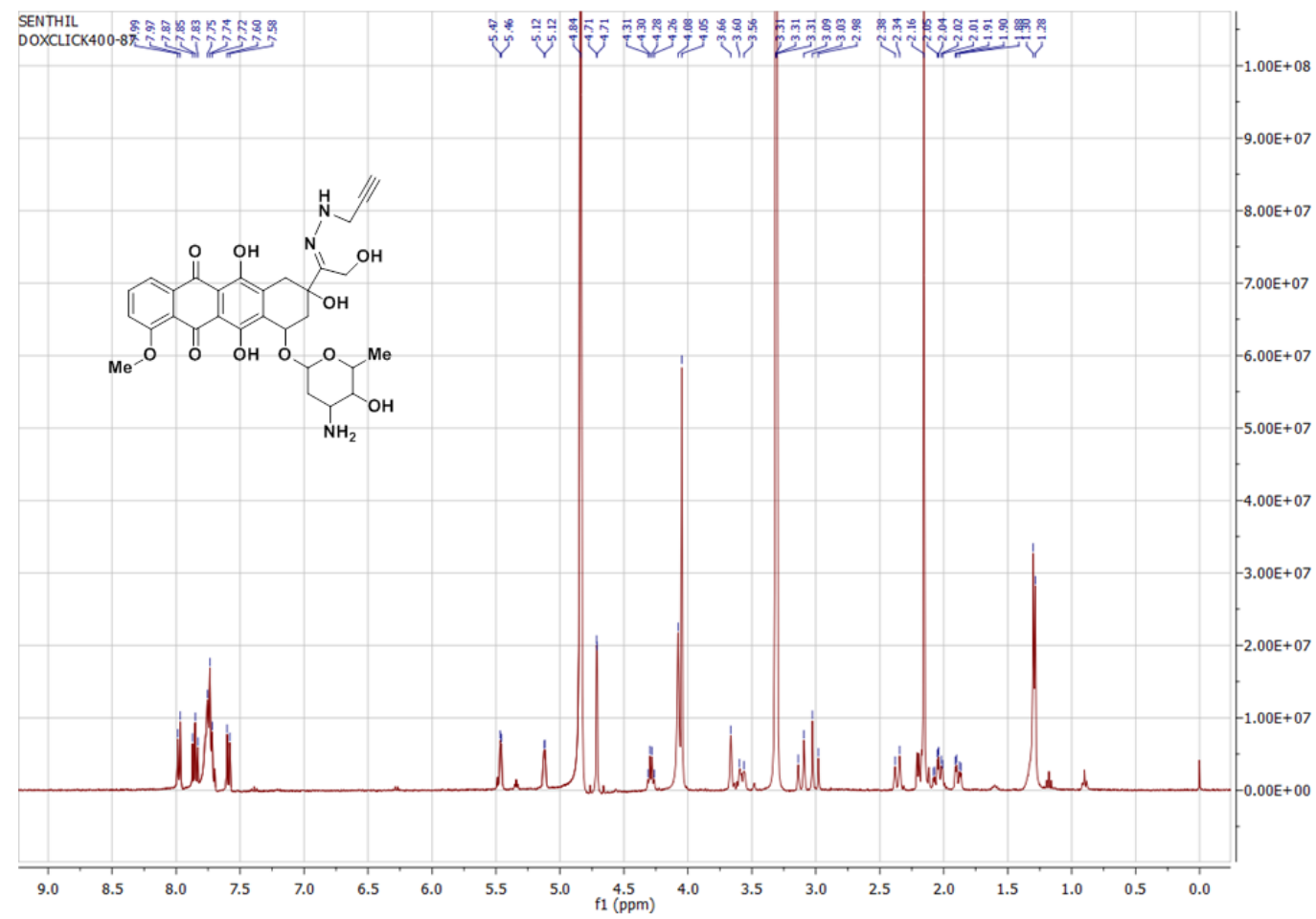

(d) Compound $6 \mathrm{NMR}$ in $\mathrm{CDCl}_{3}$. 


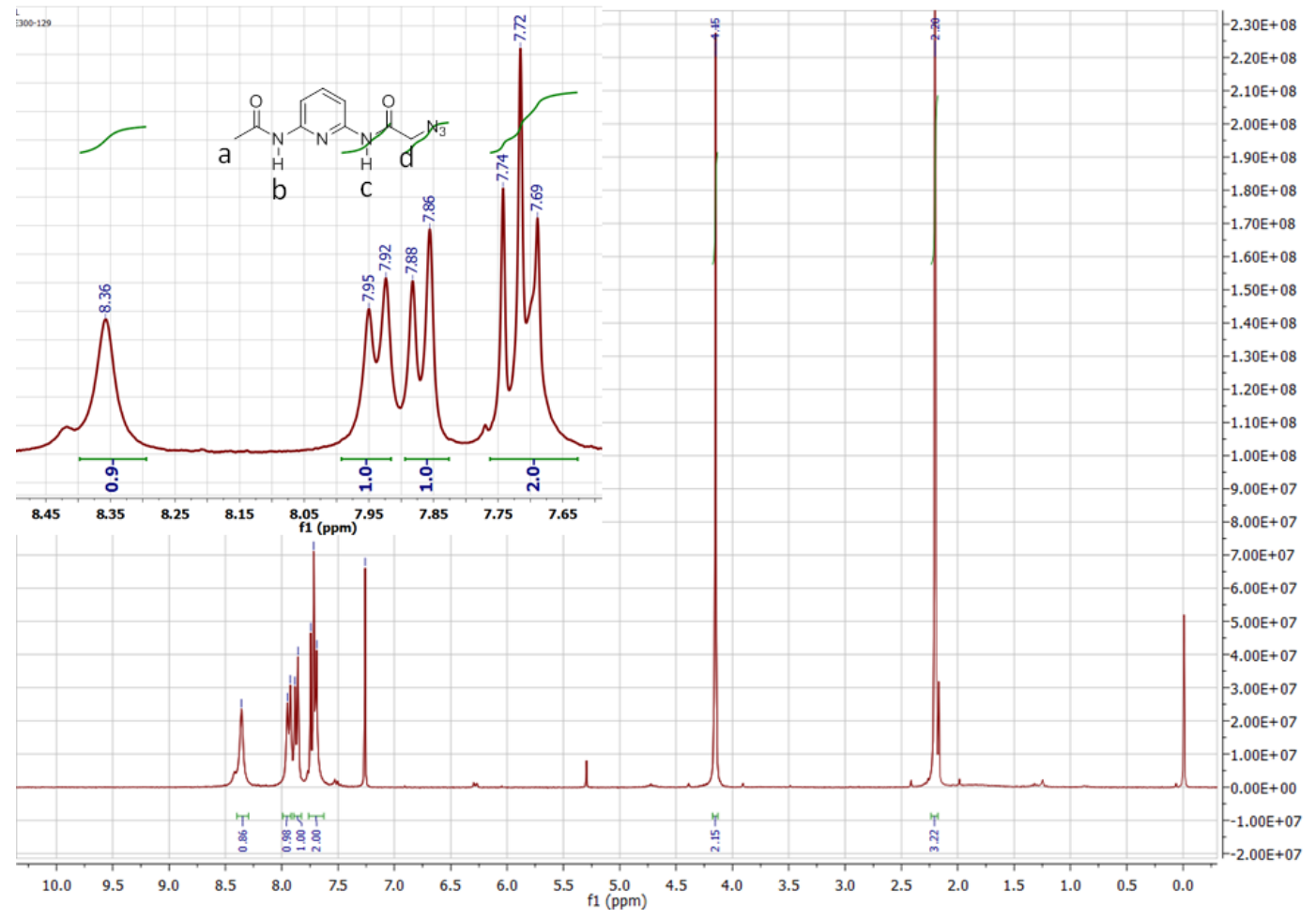

(e) Dox-Py NMR in $\mathrm{CDCl}_{3}$.

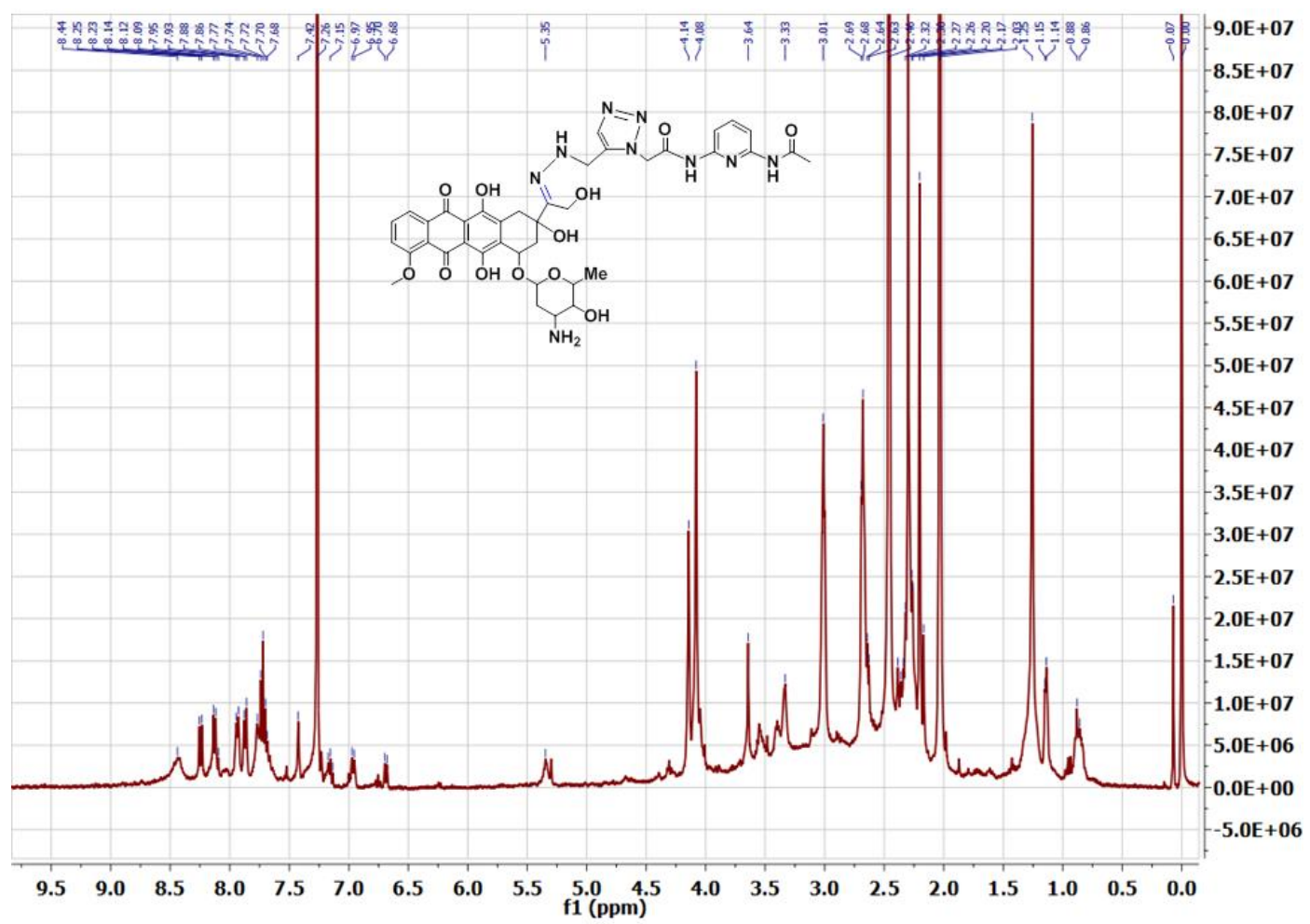

(f) PPV-C polymer NMR in DMSO- $d_{6}$. 


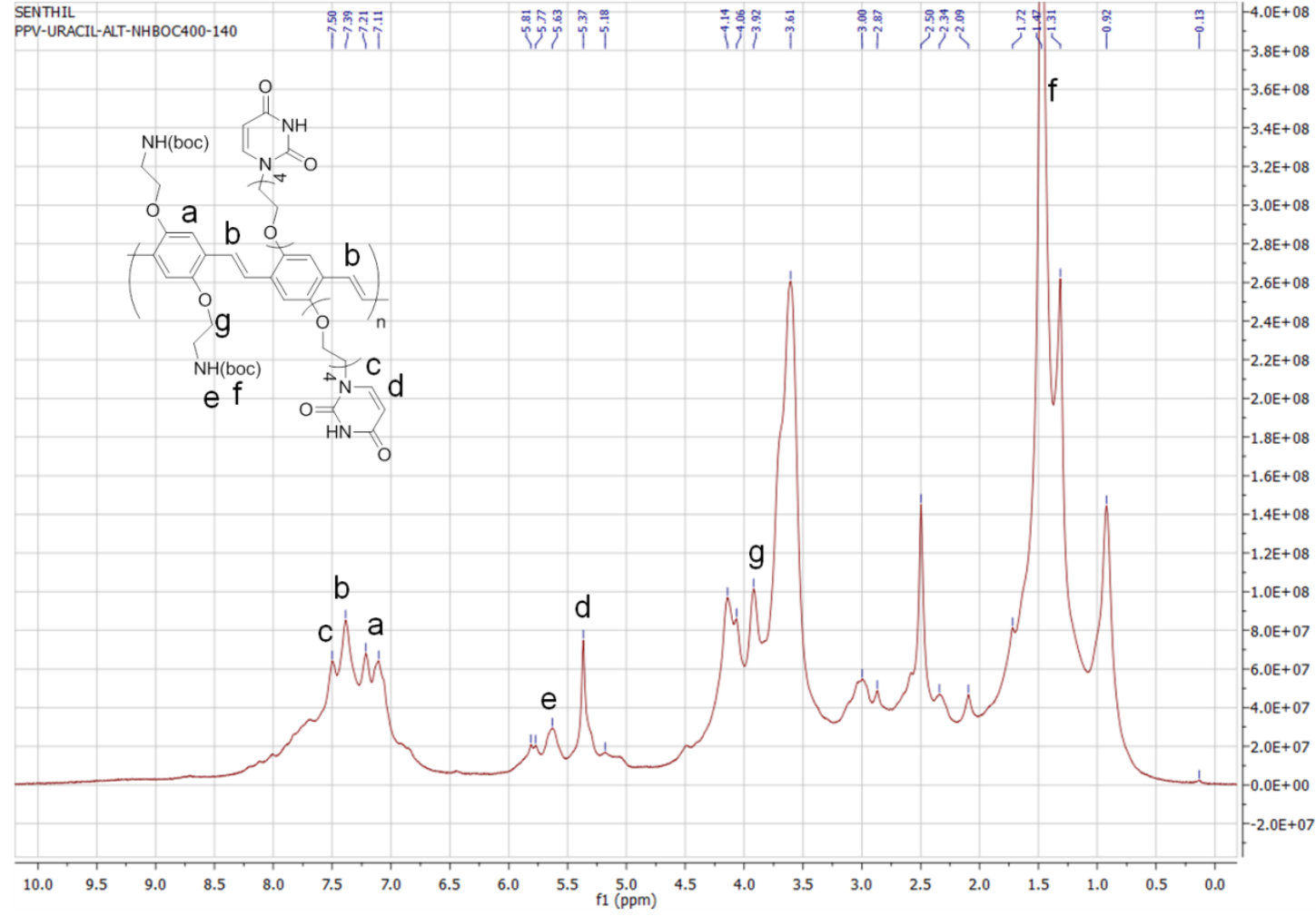

(g) PPV-NG proton NMR in THF- $d_{8}$.

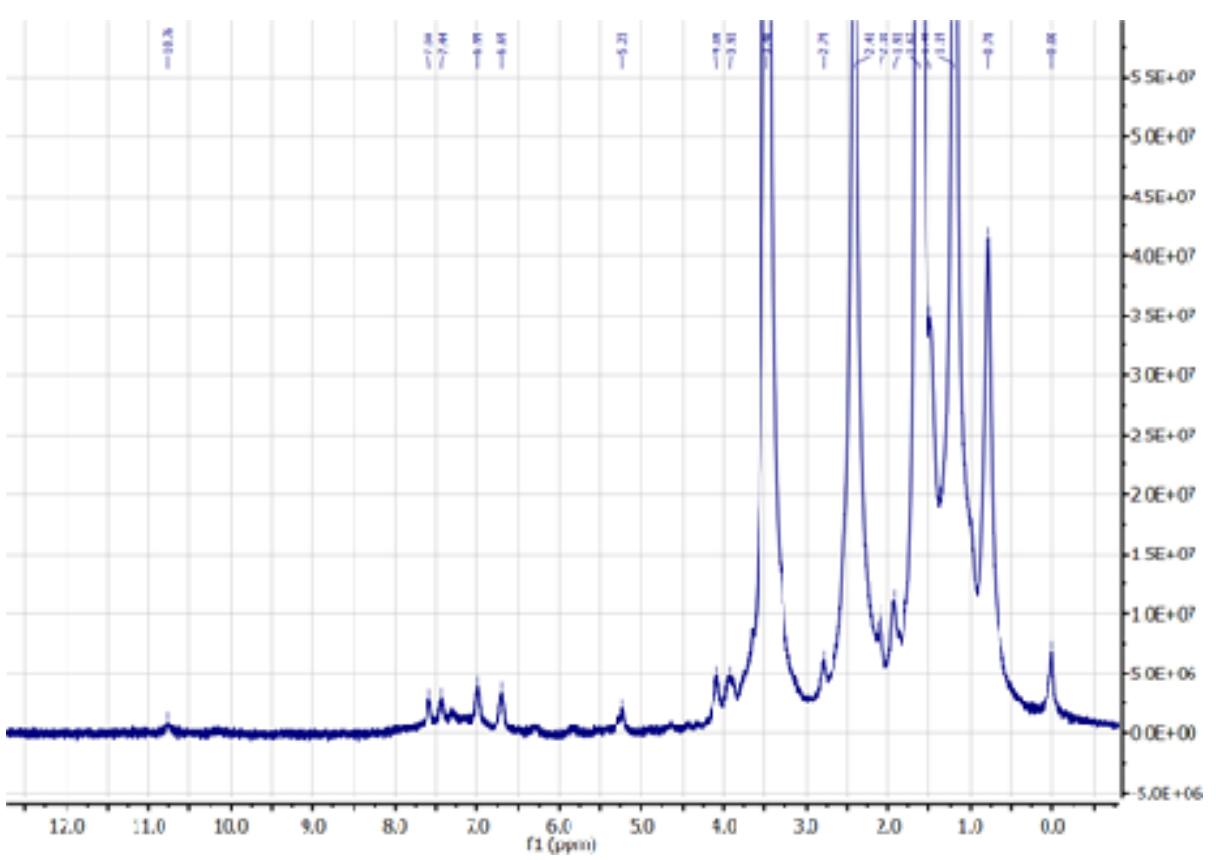

